
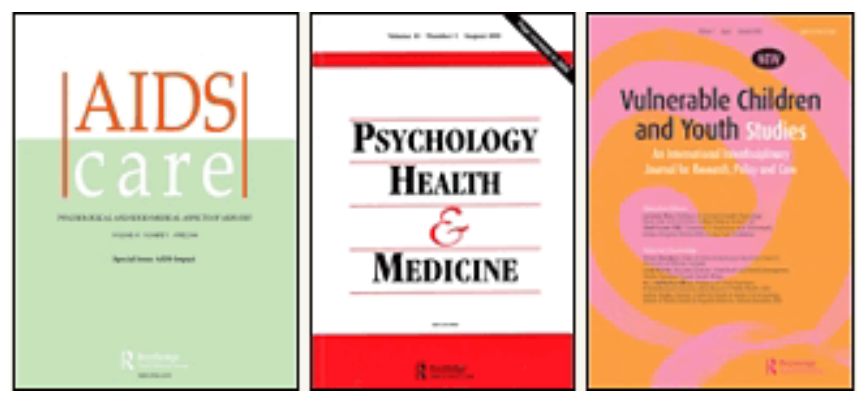

\title{
"Health regains but livelihoods lag": findings from a study with people on ART in Zambia and Kenya
}

\begin{tabular}{|r|l|}
\hline Journal: & $\begin{array}{l}\text { AIDS Care - Psychology, Health \& Medicine - Vulnerable Children } \\
\text { and Youth Studies }\end{array}$ \\
\hline Manuscript ID: & AC-2010-02-0115.R1 \\
\hline Journal Selection: & AIDS Care \\
\hline Keywords: & $\begin{array}{l}\text { Antiretroviral therapy, Food security, Livelihood strategies, Zambia, } \\
\text { Kenya }\end{array}$ \\
\hline \multicolumn{2}{|l}{} \\
\hline
\end{tabular}

\section{SCHOLARONE Manuscripts}




\section{"Health regains but livelihoods lag": findings from a study with people on ART in Zambia and Kenya}

\section{Abstract}

Although ART is increasingly accessible and eases some stresses, it creates other challenges including the importance of food security to enhance ART-effectiveness. This paper explores the role livelihood strategies play in achieving food security and maintaining nutritional status among ART patients in Kenya and Zambia. Ongoing quantitative studies exploring adherence to ART in Mombasa, Kenya $(n=118)$ and in Lusaka, Zambia $(n=375)$ were used to identify the relationship between BMI and adherence; an additional set of indepth interviews with people on ART $(n=32)$ and members of their livelihood networks $(n=64)$ were undertaken. Existing frameworks and scales for measuring food security and a positive deviance approach was used to analyse data. Findings show the majority of people on ART in Zambia are food insecure; similarly most respondents in both countries report missing meals. Snacking is important for dietary intake, especially in Kenya. Most food is purchased in both countries. Having assets is key for achieving livelihood security in both Kenya and Zambia. Food supplementation is critical to survival and for developing social capital since most is shared amongst family members and others. Whilst family and friends are key to an individual's livelihood network, often more significant for daily survival is proximity to people and the ability to act immediately, characteristics most often found amongst neighbours and tenants. In both countries findings show that with ART health has rebounded but livelihoods lag. Similarly, in both countries respondents with high adherence and high BMI are more self-reliant, have multiple income sources and assets; those with low adherence and low BMI have more tenuous livelihoods and were less likely to have farms/gardens. Food supplementation is, therefore, not a long-term solution. Building on existing livelihood strategies represents an alternative for programme managers and policy makers as do other strategies including supporting skills and asset accumulation. 


\section{Background}

As understanding of the multidimensional nature of HIV improves, it is increasingly recognized that policy and programme interventions, whether focusing on prevention, treatment, care or impact mitigation, must take into account how people's livelihoods evolve and adapt to deal with the multifaceted nature of HIV and AIDS. While more programmes are being implemented linking HIV and AIDS to livelihoods, food and nutritional security, additional evidence on the effectiveness of these interventions particularly linked with antiretroviral treatment (ART) is needed to inform policy and programming. Furthermore, insights are needed to move beyond the concept of therapeutic supplementary feeding to encapsulate broader notions of food security.

In eastern and southern Africa, evidence of the interaction between HIV and AIDS and food insecurity is mounting. Households affected by adult morbidity, mortality, with a high demographic dependency ratio are significantly more vulnerable to food security shocks than other households. These households suffer from reductions in agricultural production and income generation leading to declines in food security and distress coping strategies (Tango International 2003). A large body of evidence exists on how households and individuals respond, cope or just 'struggle' with the affects of HIV and AIDS (Barnett \& Blaikie, 1992; Baylies, 2002; Rugalema, 2000; Jayne et al., 2004; Mather et al., 2005; Arrehag, 2006; Slater \& Wiggins, 2005).

The link between nutrition and HIV and AIDS is also in evidence: malnutrition lowers the body's resistance to infection, weakens the immune system and leads to longer, more severe and frequent bouts of illness. Infections can cause appetite loss, mal-absorption, metabolic and behavioural changes that affect feeding practices thus depleting body nutrient 
stores (Gillespie \& Haddad, 2003; Gillespie \& Kadiyala 2005; Scrimshaw et al. 1997). While there is still no strong evidence that malnutrition directly increases bodily susceptibility to HIV infection, it is a plausible hypothesis (Edstrom \& Samuels, 2007). It is also increasingly accepted that HIV infection increases energy requirements: depending on whether a person exhibits AIDS-related symptoms, an HIV-positive person has 10-30\% higher energy requirements than a healthy non-infected person of the same age, sex and physical activity level (FANTA, 2004; Piwoz, 2004).

ART is now becoming increasingly available in Sub-Saharan Africa with some public health services providing antiretroviral drugs free of charge, including Zambia. Studies are also showing, against expectations, that levels of adherence to ART in Sub-Saharan Africa are relatively high (e.g. Mills et al 2006). With increasing accessibility, it is expected that some stresses placed on individuals, households and communities may be alleviated. However, it throws up other challenges. There is growing agreement that adherence to ART and its efficacy are significantly influenced by access to adequate food and nutrition (Piwoz, 2004; Sadler, 2006; Byron et al, 2006, Friis 2006). Generally, adequate nutrition is important to support recovery from opportunistic infections and for reversing weight loss, as well as for malnourished people embarking on ART (Samuels and Simon, 2006).

The above picture leads to the following questions: How are people on ART maintaining food security and/or achieving food consumption levels that are sufficient enough for them to stick to their medications? What livelihood strategies are they developing to assist them in the process? Where food supplementation is not given, how do people manage and what challenges do they face? And is food supplementation the best option in all cases?

To answer such questions, ODI and the Population Council carried out a study in Mombasa, Kenya, and Lusaka, Zambia between September 2006 and January 2007. Both countries have generalized HIV epidemics - HIV prevalence is $7.8 \%$ in Kenya and $14.3 \%$ in Zambia 
(UNAIDS, 2009; ZDHS, 2008). Both have considerable numbers of people on ART: in December 2007, 177,000 people were receiving ART in Kenya and 151,999 in Zambia (WHO, 2008).

\section{Methodology}

The research was nested in studies exploring adherence to ART: in Kenya, data from an existing questionnaire administered to people receiving ART from Mombasa General Hospital was used ( $n=118)$; in Zambia, additional questions on food security and livelihoods were added to a questionnaire administered with people on ART in 2 low-income highdensity residential areas in Lusaka $(n=375)$. All respondents were in the non-intervention arm of the study and had been on ART for 18 or more months. Additional qualitative data (indepth interviews (IDIs) and focus group discussions) were collected; in order to select this qualitative sample, socio-demographic, adherence, and body mass index (BMI) data from the quantitative studies were analyzed. A sub-sample of 32 respondents across both countries were interviewed and grouped into four categories according to adherence and nutritional status (see Table 1). IDIs were also undertaken with people in the clusters or livelihood networks (Samuels et al, 2006) of those on ART $(n=64)$ to understand their role in supporting adherence and food security of those on ART. Existing tools for measuring food security (e.g. FANTA, 2007) were used and a positive deviance (PD) approach was applied - a situation where some people use uncommon and beneficial practices giving them better health outcomes than others in their community (see e.g. Pascale, et al, 2010; and Marsh et al, 2002); through examining such practices possibilities of replicating and/or scaling are revealed (see Table 1).

\section{Results}




\section{Food consumption: Meals, diets and snacks}

The quantitative data in Zambia showed the majority of people on ART were food insecure. In both the quantitative and qualitative data, most people on ART in both Zambia and Kenya (15/16 and $11 / 16$ respectively for the qualitative data) reported frequently missing meals if food and/or money were unavailable. Missing meals often had a seasonal character, with people missing more meals during the rainy season, when also cash earning opportunities are reduced.

"What causes (missing of meals) is that sometimes you can have mealie meal but no relish or charcoal or money to buy these things. So you sleep without eating anything until the next day when you go to look for money or credit you buy charcoal you cook and eat (man, 46, Lusaka)"”.

There is more dietary diversity in Kenya (see Table 2): snacking plays an important role in people's dietary intake, and is particularly prevalent in Kenya, with many people snacking around 3 times per day. In Zambia there is less variety of snacks, with people snacking on seasonal foods; ability to snack is also related to availability of cash. This shows the increased availability of both cash and food variety in the Mombasa local economy.

\section{Food access - purchase, food supplementation, livelihood networks and farms}

Food purchase. Most people in both countries purchase food from the markets or obtain food stuffs on credit from shops/stalls; as such, they are subject to price fluctuations and high prices. In order to purchase food people engage in livelihood activities to earn cash. People also draw on assets or resort to loans and credit schemes. In both Zambia and Kenya, the majority of quantitative survey respondents indicated that they engage in selfemployment/business ( $41 \%$ and $52 \%$ respectively). In the qualitative study in Kenya, the

\footnotetext{
${ }^{1}$ This quote and the remaining quotes are all from people living with HIV and on ART
} 
majority of respondents were salaried (14/16), while in Zambia most engaged in casual labour/piecework (12/16).

For those owning property, renting out rooms is key to providing a regular source of income, often used as a capital outlay for starting or feeding back into businesses and buying food. As well as providing a regular income, tenants are also a source of food and support, with give-and-take relationships developing between the tenant and owner. People with property, tenants and therefore a regular income were found to have the best nutritional status and adherence to ART - the "best case scenario", described further below.

In Kenya loans were also important for obtaining cash: people borrowed from individuals including relatives, received salary advances or borrowed from formal credit schemes or "merry go-rounds" (informal group savings schemes). In Zambia, a few respondents were members of informal groups, but none had received a loan from formal schemes.

Food supplementation. The majority of respondents (15/16) in Zambia had received food supplementation (“... without these foods, we could have died of hunger"). In Kenya, the majority of respondents had heard about food supplementation programmes, but only 2 had benefitted. Food supplementation in Zambia is received monthly and includes wheat, soya beans, beans, peas, cooking oil, maize, eggs and kapenta (dried fish). All respondents shared with their families; some also shared with neighbours, friends and others in their livelihood network. People share what they have on the tacit understanding that they will also receive when in need. Thus food supplementation for those who received it represented a life-line enabling them both to eat and to develop social capital. Some also spoke about selling their rations in order to buy other food. 
"Yes, we share with people in this house and my neighbours when they ask for it and I give them to give their children and because they assist me with their wheelbarrow, so I give them every time" (woman, 49, Lusaka).

Challenges with food supplementation include unpredictability and infrequency of supply as well as discrepancies between the amounts people received. The quality of the food was also questioned, with people saying it caused initial health problems.

Livelihood networks. Members of livelihood networks, including family members, friends and shopkeepers, provide money, food, do household chores, and provide emotional support. In the qualitative study in Kenya, family members, including parents (particularly mothers), siblings, spouses and in-laws were identified as the most important members of livelihood networks. In Zambia, while family and relatives were a key source of support, neighbours were repeatedly mentioned as playing an important role in the survival of households and individuals. Daily survival depended strongly on proximity and immediacy, i.e. being close to someone and therefore able to respond quickly, or immediately, as is often the case with neighbours. Tenants, members of support groups and Home Based Care (HBC) teams living nearby were also important in these proximal networks. Though relatives were important, because they were often living at a distance, they were only turned to when needs were large, e.g. when someone wanted a major outlay of money or when the effects of illness were becoming overwhelming.

"If things become difficult, we ask from our neighbours ... I remember asking for salt last month ..yesterday (in return) I gave my neighbour some tomatoes" (woman, 38, Lusaka).

Farms or gardens. Despite being urban based, some respondents in both countries have farms or gardens: in Kenya, $5 \%$ of respondents from the quantitative and 6/16 respondents from the qualitative study reported engaging in farming activities. Twelve percent of 
respondents in the quantitative study in Zambia mentioned having a farm and 9/16 respondents in the qualitative study reported having a garden or field for growing food.

Garden or farm produce represents a key food source; additionally small amounts of vegetables are sold to raise money to buy other foodstuffs. Produce is also crucial in the exchange relationships which underpin livelihood networks.

\section{Health rebounding but livelihoods lagging}

The majority of respondents had experienced major set-backs in their livelihoods because of illness. With ART, their health has rebounded but livelihoods lag behind:

"Long time ago, I never used to feel good but this time I am feeling well, I have energy and power. (Before) I only used to manage washing the dishes (now) I am fit just like I used to be. I sweep the house and carry 20 litres of water (women, 21, Lusaka).

Most respondents had more secure livelihoods before they became sick and many have moved down a continuum of livelihood strategies from high to low return activities. Some moves can be explained by the life cycle, i.e. as people get older they often become less productive. But this is not always the case and in many instances the decline has resulted from sickness.

IIIness has resulted in the loss of jobs, the sale of assets, the collapse of traditional safety nets (e.g. reliance on family members) and a reduction in standards of living and quality of life. Although ART means that the majority have returned to their previous health status, their livelihood activities are degraded, making it difficult to recover their previous standards of living.

"The standard I was living in before getting HIV was a bit higher as I had a husband who was rich. I have not yet attained that (again)"(woman, 32, Kenya). 


\section{Discussion}

Since food supplementation is not a long-term solution, findings from this study highlight the importance of livelihood strategies in helping people on ART adhere to medication regimens and achieve good nutrition. Table 3 explores characteristics of people in the best (showing PD behaviours)(As) and worst case (Ds) scenarios and shows, for instance, that in both Zambia and Kenya the As have a greater number of assets (farms, rooms to rent), were more connected to the formal sector, and had someone to fall back on in times of need compared to Ds who had more tenuous livelihoods, were less likely to have farms/gardens, and were more likely to rely on piecework. While in Kenya, the As tended to be single, live in smaller households and be more educated than the Ds, this was not the case in Zambia showing, perhaps less differentiation between people but also where people were recruited into the study, i.e. the central hospital in Mombasa and the urban compounds in Lusaka.

Responding to these findings, particularly from the best case scenarios, four areas in which support could be provided in order to bolster livelihood strategies include: skills, livelihood networks, assets and cash or food transfers (see also Russell et al, 2007).

Skills-provision and education are just as important, if not more so, for people on ART, who may need to rebuild confidence, regain and build new skills. Findings show that those who are more educated and connected to the formal sector have more secure livelihoods. Health services could establish linkages with programmes that increase skills and opportunities for earning income and building assets.

The study shows that day-to-day relationships with neighbours and others who live in close proximity are crucial. These mutual support relationships consist of sharing food and tasks, e.g. looking after children or accompanying someone to the clinic. Through such livelihood networks an individual's social capital is built and maintained. Ways of building on these 
informal support structures and transforming them into more durable or long-term livelihood structures needs to be further explored.

People with assets were found to have more secure livelihoods and were better able to adhere to their drug regimen. People on ART are now well enough to return to earning a livelihood, but opportunities are lacking. This is partly because they had to draw on their assets during their sickness, but also because they previously did not envisage having a future and therefore did not plan or prepare for one. Now with ART increasingly available and free in many countries, and with people seeing a remarkable improvement in their health status, food security and therefore livelihood security becomes crucial to support adherence and assist them with longer term security. One means of promoting opportunities is through supporting the development of an asset base.

Four asset domains can be identified:

a) Property - those who had a room to rent gained a regular income and were more secure. Enabling wider property ownership through micro-credit, targeted construction loans, and/or cooperative or partnership agreements could have widespread benefits;

b) Land - land owners are more secure than the landless, more able to access food and maintain a balanced diet. Ways of encouraging people to acquire land, perhaps cooperatively, need to be explored;

c) Urban farming and gardening - those with gardens or farms had better access to food. Urban gardening and farming should, therefore, be encouraged amongst people on ART. A further strategy could involve supporting cultivation of crops through subsidized inputs, both for cash and subsistence purposes; and

d) Savings - different forms of micro-credit could enable HIV-positive people or/and people on ART to acquire an asset base. While such schemes are widespread in many countries, few have been set up for, or have included HIV-positive people or 
people on ART (though see Pinault, 2007). In Kenya, informal group savings schemes are effective means of income smoothing and saving but were not found in Zambia or were not utilized by respondents. Further South-South learning in this area could be encouraged.

In situations when people have started seeing improvements through using ART, cash transfers may be more effective than food transfers. But when people are too sick to work food is needed for survival and to rebuild strength in order to re-engage in livelihood activities. Food supplementation, however, needs to be better targeted, better time-defined and it should be viewed as an addition to an existing livelihood, not a replacement. Often $\mathrm{BMI}$ is used as a key indicator of whether someone should receive food supplementation. While BMI is important, findings from the study suggest that more focused and context specific indicators are needed. These could include household size, number of income earners, kind of employment and the existence of a farm or garden. It is also important to define for how long each person will receive food supplementation; the study found that recipients were unsure when the supplementation would end, how often and how much they would receive, and why some people received more. Organisations providing food should encourage those in good health to continue their livelihood activities and link recipients with other groups, including those involved in urban farming, microfinance and livelihood programming.

These four overlapping and inter-linked areas of input and support are not exclusively for HIV-positive people on ART and indeed many such programmes have been initiated targeting the poor and vulnerable more generally. What is new, however, is that previously HIV-positive people and those on ART where not considered to have a future and even if they did survive a few years, their ill health prohibited them from meaningful involvement in livelihood security. Now, with ART, this is no longer the case. 


\section{References}

Arrehag, L., de Vylder, S., Durevall, D., \& Sjöblom, M. (2008). The Impact of HIV/AIDS on Livelihoods, Poverty and the Economy of Malawi. Sida Studies No. 18. Swedish International Development Cooperation Agency, Stockholm.

Barnett, T. \& Blaikie, P. (1992). AIDS in Africa - Its present and future impact. London, Belhaven Press.

Baylies, C. (2002). The Impact of AIDS on rural households in Africa. Development and Change, Vol. 33(4): 611-632.

Byron, E., Gillespie, S. and Nangami, M. (2006). Integrating Nutrition Security with Treatment of People Living with HIV: Lessons being Learned in Kenya. IFPRI/RENEWAL

Edstrom, J. and Samuels, F. (2007). HIV, Nutrition, Food and Livelihoods in Sub-Saharan Africa: Evidence, debates and reflections for guidance. Report prepared for DFID

FANTA, (2007). Household Food Insecurity Access Scale (HFIAS) for Measurement of Food Access: Indicator Guide VERSION 3.

FANTA, (2004). Food and nutrition implications for of Antiretroviral therapy in resource poor settings. Technical Note No. 7.

Friis, H. (2006). Micronutrient Interventions and HIV infection: a review of current evidence. Tropical Medicine and International Health 11(12):1-9 
Gillespie, S. \& Kadiyala, S. (2005). 'Chapter One' in HIV/AIDS and Food and Nutrition Security: from Evidence to Action. IFPRI Food Policy Review.

Gillespie S, \& Haddad L. (2002). Food security as a response to AIDS, in AIDS and food security: essays by Peter Piot; Per Pinstrup-Andersen; Stuart Gillespie; Lawrence Haddad. Washington, DC: IFPRI.

Jayne, T. S., Villarreal, M., Pingali, P. \& Hemrich, G. (2004). 'Interactions between the Agricultural Sector and the HIV/AIDS Pandemic: Implications for Agricultural Policy', ESA Working Paper No. 04-06, March 2004, Agricultural and Development Economics Division, FAO, Rome.

Marsh, D.R., Pachon, H., and Schroeder D.G. (2002). Supplement: The Positive Deviance Approach to Improve Health Outcomes: Experience and Evidence from the Field. Food and Nutrition Bulletin 23(4):3-135.

Mather, D., Donovan, D., Jayne, T., Weber, M., Mazhangara, E., Bailey, L., Yoo, K., T. Yamano, T., \& Mghenyin, E. (2005). A Cross-Country Analysis of Household Responses to Adult Mortality in Rural Sub Saharan Africa: Implications for HIV/AIDS Mitigation and Rural Development Policies. MSU International Development Working Paper No. 82. East Lansing: Michigan State University.

Mills E.J., Nachega J.B., and Buchan I., et al. (2006). Adherence to antiretroviral therapy in sub-Saharan Africa and North America: a meta-analysis. Jama 296(6): 679-690.

NASCOP, (2005). National AIDS and STI Control Programme, Ministry of Health, Kenya. AIDS in Kenya, $7^{\text {th }}$ ed. 
Pascale, R., Sternin, J., and Sternin, M. (2010). The Power of Positive Deviance: How Unlikely Innovators Solve the World's Toughest Problems. Harvard Business Press.

Paton N.I., Sangeetha, S., Earnest, A., \& Bellamy, R. (2006). The impact of malnutrition on survival and the CD4 cell response in HIV-infected patients starting antiretroviral therapy. HIV Medicine, 7:323-330.

Pinault, D., (2007). “Lessons From Care's Classe Intambwe Model Addressing The Longer Term Food And Livelihood Security Of PLWAS And Those At Risk, CARE International in Rwanda".

http://www.odi.org.uk/pppg/poverty and inequality/Events/2007 Food HIV AIDS/Presentati ons/5.\%20Pinault\%20presentation.pdf).

Piwoz, E. (2004). Nutrition and HIV/AIDS: evidence, gaps, and priority actions. USA Agency for International Development (USAID)

Piwoz E.G. \& Preble, E.A. (2000). HIV/AIDS and nutrition: A review of the literature and recommendations for nutritional care and support in Sub-Saharan Africa. Washington, DC: SARA Project.

Rugelama, G. (2000). 'Coping or Struggling? A Journey into the Impact of HIV/AIDS in Southern Africa'. Review of African Political Economy 86:537-545. Roape Publications Ltd.

Russell, S., Seeley, J., Ezati, E., Wamai, N., Were, W., \& Bunnell, R. (2007). Coming back from the dead: living with HIV as a chronic condition in rural Africa. Health Policy and Planning 2007; 22:344-347. 
Sadler, K.. (2005) Community-based Therapeutic Care in HIV-affected populations. Transactions of the Royal Society of Tropical Medicine and Hygiene. 296: 1-4

Samuels, F., Drinkwater, M. \& McEwan, M. (2006). Understanding HIV/AIDS and livelihoods: The contribution of longitudinal data and cluster analysis, ODI Briefing Paper 8. http://www.odi.org.uk/resources/download/398.pdf

Samuels, F. \& Simon, S. (2006). Food, Nutrition and HIV: What next? ODI briefing Paper 7. (http://www.odi.org.uk/publications/briefing/bp aug06 hiv nutrition.pdf

Scrimshaw, N. \& SanGiovanni, J.P. (1997). Synergies of nutrition, infection and immunity: An overview. American Journal of Clinical Nutrition, 66: 464S-477S.

Slater, R. \& Wiggins, S. (2005). Responding to HIV/AIDS in agriculture and related activities. ODI NRP http://www.odi.org.uk/nrp/98.pdf

TANGO International, (2003). HIV/AIDS and Vulnerability: An Overview of Micro, Meso, and Macro Level Implications. Johannesburg, South Africa Technical Consultation on Measuring Vulnerability in the Light of the HIV/AIDS Pandemic http://www.sarpn.org.za/documents/d0000600/index.php

UNAIDS, (2009). AIDS epidemic update: November 2009.

USAID, (1992). Policy Determination: Definition of Food Security. 
WHO, (2008). Towards Universal Access: Scaling up priority HIV/AIDS interventions in the health sector Progress Report 2008.

ZDHS, (2008). Zambia Demographic and Health survey, 2007. 


\section{Table 1 Nutritional Status and Adherence scenarios}

Respondents from the quantitative studies were categorized into 4 groups:

A) Adequate (BMI > 18) nutritional status and good adherence (>95\%);

B) Adequate $(\mathrm{BMI}>18)$ nutritional status and poor adherence $(<95 \%)$;

C) Inadequate $(\mathrm{BMI}<=18)$ nutritional status and good adherence $(>95 \%)$;

D) Inadequate $(\mathrm{BMI}<=18)$ nutritional status and poor adherence $(<95 \%)$

\begin{tabular}{|c|c|c|c|}
\hline & $\%$ & & ence \\
\hline & & High & Low \\
\hline & High & $A$ & $B$ \\
\hline & Low & C & D \\
\hline
\end{tabular}

An individual who manages to achieve food and livelihood security resulting in a high BMl as well as high levels of adherence (As) could be said to be engaged in positive deviance behaviours. The worse case scenarios are the Ds who are unable to achieve both foods security or adequate levels of adherence. 


\section{Table 2 Dietary Diversity}

In Kenya for breakfast tea, mandazi, mahamri with bread, fruit, cassava, sweet potato cooked with coconut, porridge, boiled egg, sausage, chapatti and liver was mentioned; lunch could consist of ugali (maize meal porridge) with beans, fish, sukuma, cabbage or green grams, rice with beans, kunde, mchicha, chapatti, chips, fish, chicken, dried meat and fruits like bananas; and evening meals could be made up of a bowl of mboga and ugali variations were bananas mixed with spinach or mchicha, boiled vegetables, beans, meat/sausage and onions, white rice, sukuma wiki.

In Zambia, people reported having tea and bread, rice, porridge with soya or groundnuts were for breakfast; for lunch and dinner respondents reported eating nshima (maize meal porridge) with relish such as aubergine, impwa, kapenta, beans, bondwe, eggs, rape, kalembula, chibwabwa, vinkubala, cabbage, fish or meat. 


\begin{tabular}{|c|c|c|}
\hline $\begin{array}{l}\text { Variables affecting livelihood } \\
\text { security }\end{array}$ & Kenya & Zambia \\
\hline $\begin{array}{l}\text { Marital status \& household } \\
\text { size }\end{array}$ & $\begin{array}{l}\text { Respondents in group A tended } \\
\text { to be single and live in smaller } \\
\text { households, while those in } \\
\text { group D were married and lived } \\
\text { in larger households. }\end{array}$ & $\begin{array}{l}\text { No difference between As and } \\
\text { Ds. }\end{array}$ \\
\hline Education & $\begin{array}{l}\text { Respondents in group A were } \\
\text { more educated than those in } \\
\text { group D, with all having had } \\
\text { some form of education (two } \\
\text { group A respondents reached } \\
\text { secondary level, while only two } \\
\text { group D respondents even } \\
\text { reached primary level). }\end{array}$ & $\begin{array}{l}\text { No difference between As and } \\
\text { Ds. }\end{array}$ \\
\hline Employment: & $\begin{array}{l}\text { Respondents in group A tended } \\
\text { to be more involved in } \\
\text { formal/permanent employment } \\
\text { and therefore had higher } \\
\text { earning capacities than those in } \\
\text { group D }\end{array}$ & $\begin{array}{l}\text { Respondents in group A } \\
\text { tended to have more } \\
\text { permanent ways of earning an } \\
\text { income; they also had assets } \\
\text { with which they could earn } \\
\text { money, including rooms to rent } \\
\text { out and farms where produce } \\
\text { was used both for } \\
\text { consumption and sale. In } \\
\text { group D, piecework was key to } \\
\text { their earnings, though one } \\
\text { person did report having a } \\
\text { more permanent job as a } \\
\text { hairdresser }\end{array}$ \\
\hline Coping: & $\begin{array}{l}\text { Respondents in group A were } \\
\text { much more self-reliant than } \\
\text { those in group } D \text {, of whom all } \\
\text { except one were dependent on } \\
\text { others. }\end{array}$ & $\begin{array}{l}\text { Respondents in group A were } \\
\text { able to be self-reliant, though } \\
\text { they often had one key person } \\
\text { who they relied on; in group D, } \\
\text { respondents had a variety of } \\
\text { coping strategies, including } \\
\text { borrowing from various people. }\end{array}$ \\
\hline Savings and credit: & $\begin{array}{l}\text { Two people in group } A \text { had } \\
\text { savings accounts; none had a } \\
\text { savings account in group } D \text {, } \\
\text { though one was a member of a } \\
\text { merry-go-round. }\end{array}$ & $\begin{array}{l}\text { None had savings accounts or } \\
\text { were members of informal } \\
\text { savings schemes. }\end{array}$ \\
\hline Food consumption: & $\begin{array}{l}\text { Respondents in group A had } \\
\text { access to sufficient, diverse, } \\
\text { and often relatively expensive } \\
\text { food, eating at least three } \\
\text { meals a day and often snacking } \\
\text { in between. For respondents in } \\
\text { group D, skipping meals was } \\
\text { more common and the variety } \\
\text { of food was more limited, with } \\
\text { less expensive foods being } \\
\text { consumed when compared to }\end{array}$ & $\begin{array}{l}\text { While respondents in group } A \\
\text { did buy food items, their farms } \\
\text { played an important role in } \\
\text { their food security strategies; } \\
\text { in group } D \text { none had farms and } \\
\text { they relied on purchasing food } \\
\text { or receiving it from others. }\end{array}$ \\
\hline
\end{tabular}


